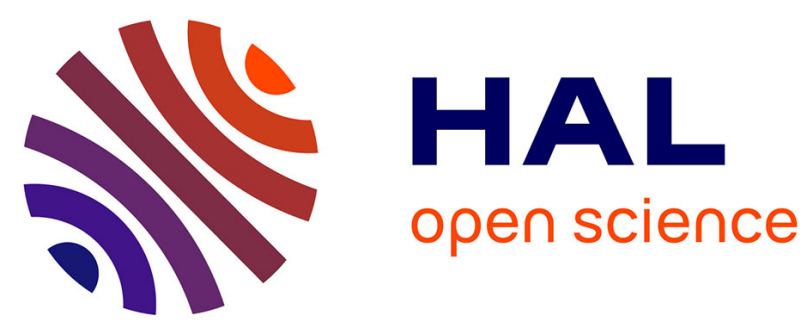

\title{
FABRICATION OF SILICON-ON-INSULATOR MEM RESONATORS WITH DEEP SUB-MICRON TRANSDUCTION GAPS
}

\author{
N.-D. Badila, C. Hibert, M. Mazza, A.M. Ionescu
}

\section{- To cite this version:}

N.-D. Badila, C. Hibert, M. Mazza, A.M. Ionescu. FABRICATION OF SILICON-ON-INSULATOR MEM RESONATORS WITH DEEP SUB-MICRON TRANSDUCTION GAPS. DTIP 2006, Apr 2006, Stresa, Lago Maggiore, Italy. 4 p. hal-00189283

\section{HAL Id: hal-00189283 https://hal.science/hal-00189283}

Submitted on 20 Nov 2007

HAL is a multi-disciplinary open access archive for the deposit and dissemination of scientific research documents, whether they are published or not. The documents may come from teaching and research institutions in France or abroad, or from public or private research centers.
L'archive ouverte pluridisciplinaire HAL, est destinée au dépôt et à la diffusion de documents scientifiques de niveau recherche, publiés ou non, émanant des établissements d'enseignement et de recherche français ou étrangers, des laboratoires publics ou privés. 


\title{
FABRICATION OF SILICON-ON-INSULATOR MEM RESONATORS WITH DEEP SUB- MICRON TRANSDUCTION GAPS
}

\author{
Nicoleta Diana BADILA ${ }^{1}$, Cyrille HIBERT ${ }^{2}$, Marco MAZZA ${ }^{1}$, Adrian M. IONESCU ${ }^{1}$ \\ ${ }^{1}$ Electronics Laboratory, ${ }^{2}$ Center of Micro-Nano Technology, Swiss Federal Institute of Technology, \\ Lausanne, Switzerland \\ \{nicoleta-diana.badila, cyrille.hibert, marco.mazza, adrian.ionescu\}@epfl.ch
}

\begin{abstract}
The paper proposes and validates a low-cost technological process for realizing fully mono-crystalline MEM resonators with deep sub-micron transduction gaps on SOI substrates. The MEM resonators are designed to work as BLR (bulk lateral resonators) in which the resonance of a suspended mass is excited and detected by lateral electrodes. For MEM BLRs, nano-scaled gaps $(<200 \mathrm{~nm})$ are essential to reduce the motional resistance in the order of few $\mathrm{k} \Omega$ as well as to avoid the use of large DC applied voltages. Only standard optical lithography with $1 \mu \mathrm{m}$ resolution and IC-compatible processing steps are employed to obtain $100 \div 200 \mathrm{~nm}$ wide gaps with very high aspect-ratios of [40:1], allowing the fabrication of high $\mathrm{Q}$ resonators expected to work into $\mathrm{MHz}$ to $\mathrm{GHz}$ range.
\end{abstract}

\section{INTRODUCTION}

Latest developments in the field of RF devices and systems show increased interest concerning the miniaturization and integration of the resonator element into the reference oscillator [1]-[3]. A large part of the efforts are focusing on silicon or silicon-on-insulator (SOI) Micro-Electro Mechanical (MEM) resonators which promise to be a viable alternative to stable but bulky quartz crystals, due to their remarkably miniaturized sizes which allow high integration levels [4]-[9].

In order to extend the operating frequencies domain in the tens of $\mathrm{MHz} \div \mathrm{GHz}$ range, the resonator size, so also the actuation area is decreasing, and it becomes challenging to maintain acceptable resonator impedance $\left(R_{m}\right)$ and power levels. The motional resistance of a MEM BLR is proportional to:

$$
R_{m} \sim \frac{g^{4}}{h^{2} \times w^{2}},
$$

where $g$ is the width, $h$ the depth and $w$ the length of the transduction gap. Therefore, in order to meet the specifications for practical applications, it is essential to decrease the gap width, while maximizing the trench aspect-ratio $(h / g)$ as much as possible. For this reason, gaps in the $100 \div 200 \mathrm{~nm}$ range, with aspect-ratios as high as $[40: 1]$ are targeted.

\section{PROCESS FLOW}

The cross-sections from Figure 1 are summarizing the fabrication sequence:

\begin{tabular}{|l|}
\cline { 2 - 2 } \multicolumn{1}{c|}{$0.5 \mu \mathrm{m} 1^{\text {st }}$ TEOS } \\
\hline $3 \mu \mathrm{m} \mathrm{BOX}$ \\
\hline Bulk Si
\end{tabular}

(a)

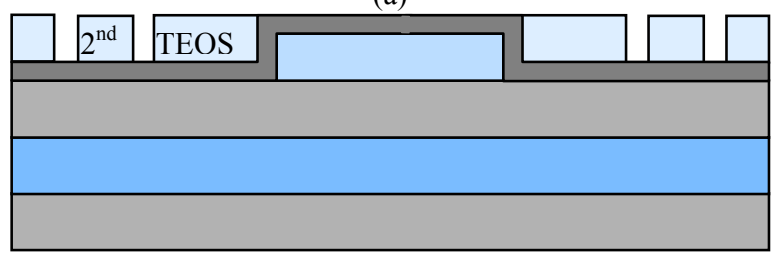

(b)

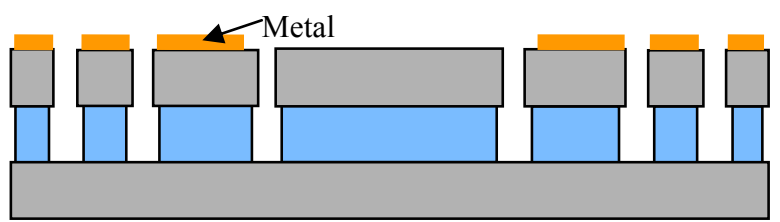

(c)

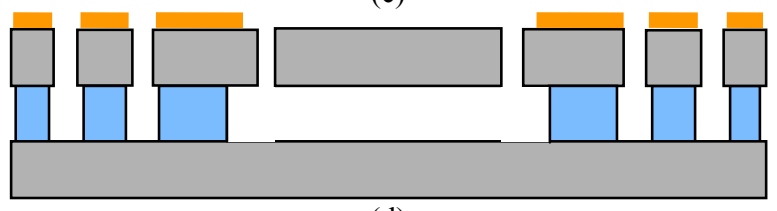

(d)

Figure 1: Process flow main steps.

The starting material is Silicon-On-Insulator (SOI) substrate, with a Si layer thickness of $1.5 \mu \mathrm{m}$ and $3 \mu \mathrm{m}$ buried oxide (BOX). The first step consists of a $0.5 \mu \mathrm{m}$ TEOS deposition, followed by patterning and etching of 
the first mask, which will define the MEM resonating structure. A polysilicon layer with a thickness of less than $100 \mathrm{~nm}$, which will serve as gap-spacer, is then deposited. At this processing step, the cross-section looks as in Figure 1.a. Next, a second TEOS layer is deposited, followed by a combination of Chemical Mechanical Polishing (CMP) and wet etch in order to expose the polysilicon layer. A second photolithography step and a dry $\mathrm{SiO}_{2}$ etch will define the resonator's electrodes. At this stage, as shown in Figure. 1.b, the hard-mask which will be used to etch the Si MEM resonator is complete. The structure is then etched with a low-frequency pulsed plasma ICP-RIE in order to avoid Si notching at the BOX interface, and the mask oxide is back-etched in BHF. Subsequently, using a third mask, the undoped polysilicon is removed from the contact area, and metal is plated. Figure 1.c illustrates the process at this step. At last, the structure is released in BHF, as depicted in Figure 1.d.

\section{NANO-GAP MASK FORMATION}

The deep sub-micron openings in the TEOS hard mask which are used to etch the nano-gaps are obtained by depositing and then selectively removing a very thin polysilicon spacer layer. The PolySi LPCVD has a good uniformity; therefore the in-wafer nano-gap mask opening variation is smaller than $\pm 5 \%$.

It is very important that after patterning the first mask, the TEOS sidewalls are very smooth and vertical. Otherwise, the polysilicon gap spacer which is following exactly the shape of the structure will be tilted and the plasma won't have directional access to the SOI layer when etching the resonators. For this reason, the first photolithography step is essential, as well as a selective, smooth oxide dry-etch recipe.

A second oxide is then deposited above the polysilicon, and then etched back with a combination of CMP and wet etch, until the spacer layer is uncovered. It is important that the polysilicon layer isn't damaged by the etching process, because later on it will be used to protect the oxide underneath during the selective dry etch for patterning the electrodes, sealing ring and contact pads. The CMP speed is highly dependent on the pattern density and size, the general rule being that some wide, high-density patterns planarize the slowest and narrow, isolated features planarize the fastest. Therefore, in some areas, the polysilicon layer will be exposed faster and it will start to erode. Since the layer thickness is of $100 \mathrm{~nm}$ or less, there is a high risk of punching through the polysilicon in the areas with a less dense pattern. This problem can be avoided by stopping the CMP before reaching the polysilicon layer, and by finishing the oxide back-etch with a short BHF step.
Special attention must be paid to the second oxide deposition. At first, LPCVD low temperature oxide (LTO) has been tested, and the electrodes were etched using BHF. The SEM images taken at this point (Figure 2.a) revealed that voids were formed during LTO deposition, which were etched faster in BHF, generating an uneven shape in the hard mask at the electrode corner in contact with the polysilicon spacer. For this reason, as shown in Figure 2.b, after etching the gaps, the trench interface with an open area was very rough, strong skirting effect being observed.

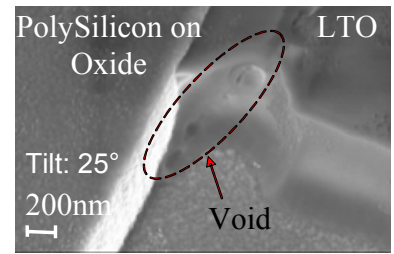

(a)

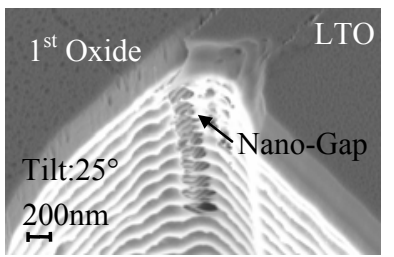

(b)
Figure 2. SEM pictures showing voids in the LTO layer after patterning the electrodes (a) and after etching the gap (b)

In order to solve this difficulty, the process flow was changed by replacing the LTO with LPCVD TEOS, which has better step-coverage and higher density, and by etching the electrodes with a selective $\mathrm{C}_{4} \mathrm{~F}_{8}$ plasma etch instead of wet BHF-etch. The results obtained with the improved process are showed in Figure 3.

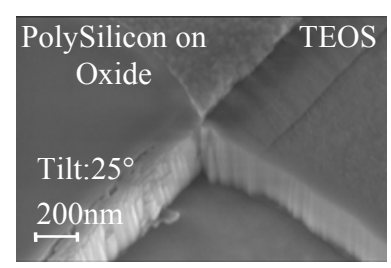

(a)

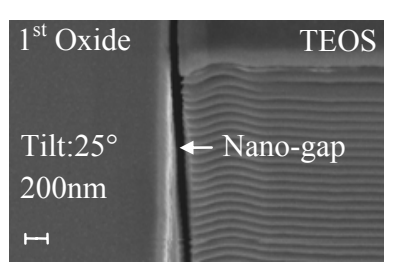

(b)
Figure 3. SEM pictures of the improved process, showing the hard mask after patterning the electrodes with a dry plasma etch (a) and the etched nano-gap (b)

\section{NANO-GAP ETCH}

One of the most critical steps of the process is the deep sub-micron gap etch. Two different techniques have been evaluated, a continuous etch-process, and the Super High Aspect Ratio Process (SHARP), developed at Alcatel Vacuum Technology.

The continuous process uses a mix of etching $\left(\mathrm{SF}_{6}\right)$ and passivating $\left(\mathrm{C}_{4} \mathrm{~F}_{8}\right)$ gases, and due to the directional ion bombardment, the passivation layer is removed at much higher rate from the bottom of the trench, exposing it to the etch. The process has the advantage of generating smooth walls, but it proved to be very sensitive to the 
angle of the hard-mask openings, caused by the first photolithography step, as shown in Figure 4:

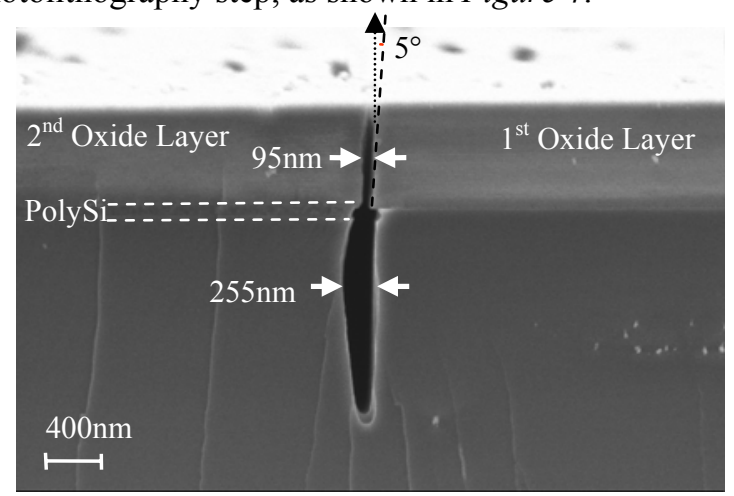

Figure 4. SEM picture of a nano-gap etched using the continuous process

In the picture above we can see that as the ions which are reaching the substrate are not coming under a $90^{\circ}$ but a slightly smaller angle, one of the trench walls is bowed, noticeably increasing the gap-width.

Better results were obtained starting from the SHARP process, based on the Bosch technique, which uses alternating etching and passivating steps to achieve high aspect ratio trenches in silicon. The Bosch process has its limitations, among which we can consider the scallopinginduced wall roughness, the large undercut and the aspect-ratio limited to maximum [30:1]. When used for etching deep sub-micron trenches, all these effects become critical, being a major limiting factor. The main improvements of the SHARP process include: (a) fastswitching of the etching and passivating steps to reduce the wall roughness, (b) raising the platen power and decreasing the pressure for a longer mean free path, (c) adding an $\mathrm{O}_{2}$ plasma step for better polymer removal and (d) decreasing the substrate temperature for a higher mask selectivity.

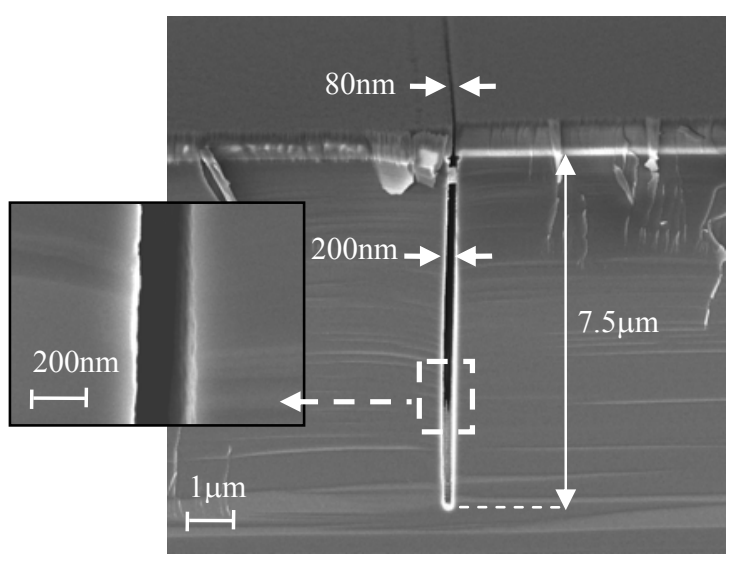

Figure 5: SEM picture of a 200nm-wide and 7.5 $\mu \mathrm{m}$-deep trench, etched with a SHARP-based process
Figure 5 shows the SEM picture of a 200nm-wide and $7.5 \mu \mathrm{m}$-deep gap etched with this technique. Aspectratios of [40:1] and low scalloping, thus smooth vertical walls have been demonstrated. The limiting factor for the achieved trench depth was the etch selectivity between the silicon and the oxide hard-mask. For further tests regarding the maximum achievable aspect ratio, thicker oxide hard-mask should be used.

\subsection{Notching Effect}

Deep Reactive Ion Etch (DRIE) processes may have different silicon etch-rates due to loading effects as the ARDE (Aspect-Ratio-Dependent-Etch) or the general loading effect by which edges of the wafer etch faster than the center. The same applies to the SHARP process, the etch-rate being more than two times lower in the nano-gap area than in the large openings. For this reason, wide opened spaces on the wafer will be overetched by as much as $150 \%$ until the nano-gaps are completely opened.

At the same time, plasma etching of silicon over an insulator layer can result in a notching problem at the silicon/insulator interface, due to trapped charges in the insulator, as it can be seen in Figure 6.a. The notch size is proportional to the etch time, so large overetch of the big openings results in significant notching effect.

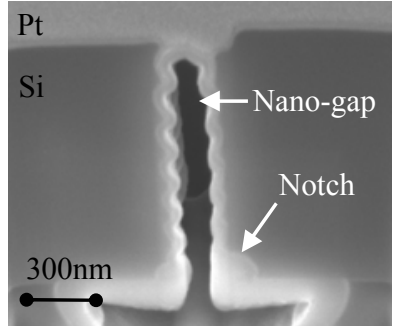

(a)

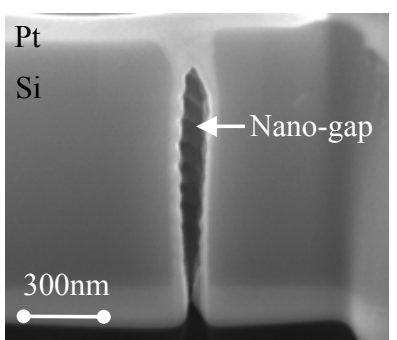

(b)
Figure 6: FIB cross-sections of fully etched nano-gaps showing (a) notching and (b) notch-free profile obtained with an Adixen AMS 200 DSE etcher. The lighter-colored material is the platinum protection deposited with the FIB.

This effect can be removed by using a low frequency pulsed substrate polarization, which allows the ions to escape, preventing the charge accumulation. We have used an Adixen AMS 200 DSE etcher and a typical notch-free result is shown in Figure 6.b.

\subsection{Skirting Effect}

One additional phenomenon related to the DRIE processes, which can cause a short between the electrodes and the resonating structure, is the so called "skirting effect". Due to over-passivation, the etch fails to entirely remove the silicon at the interface between narrow 
trenches and larger openings, producing a result as shown in Figure 7.

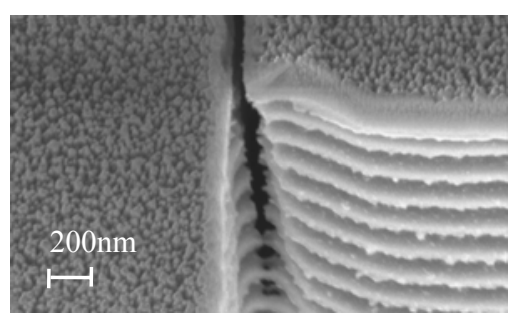

Figure 7: SEM picture of the nano-gap interface with a large opening, showing an extreme case of skirting

Since the skirting effect cannot be solved by modifying the process parameters without affecting the selectivity of the etch, the undercut and the gap profile, a special antiskirting design was needed. The design uses a smooth transition between the trench and the open area, as shown in Figure 8:

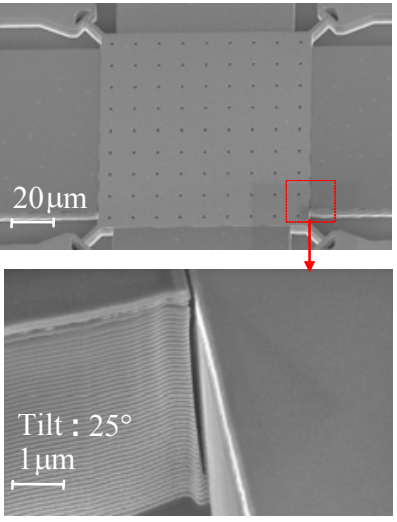

(a)

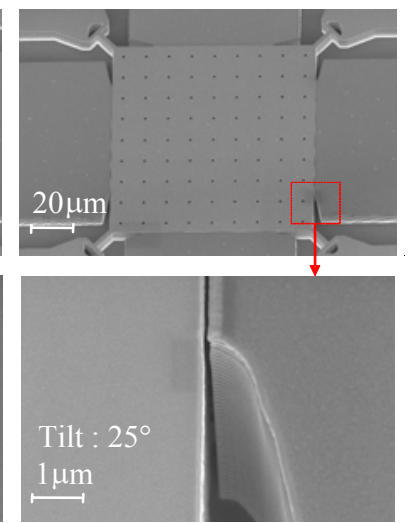

(b)
Figure 8: SEM picture of an anti-skirting designed nano-gap MEM resonator (a) and the design validation (b)

From the pictures above we can see that the anti-skirting design solves the problem completely, no skirting being observed for gaps of up to $10 \mu \mathrm{m}$-deep.

The final critical step of the process is the resonator release and oxide mask removal, by wet etching the oxide. First tests have shown that most of the structures can be successfully released with BHF and air-dried, although some of the less stiff structures suffer from release-related sticktion. In the future, supercritical drying needs to be used in order to solve the sticktion problem.

\section{CONCLUSIONS}

A fabrication process for realizing mono-crystalline MEM resonators with deep sub-micron transduction gaps on SOI substrates has been developed and validated. Gaps of less than 200nm have been obtained, using only standard optical lithography with $1 \mu \mathrm{m}$-resolution. Aspect -ratios as high as [40:1] were demonstrated, using an optimized, notch-free dry etch process based on Alcatel Vacuum Technology's SHARP. An anti-skirting design has been proposed and validated for gap depths of up to $10 \mu \mathrm{m}$, allowing the fabrication of MEM resonators with low impedance levels, without the need of high DC voltages, functioning in the hundreds of $\mathrm{MHz}-\mathrm{GHz}$ range.

\section{ACKNOWLEDGEMENTS}

This work has been funded by FP6 IST research project NANOTimer and Swiss SER Project number 03.0496-1.

\section{REFERENCES}

[1] C.T.-C. Nguyen, R.T. Howe, "An Integrated CMOS Micromechanical Resonator High-Q Oscillator", IEEE Journal of Solid-State Circuits, vol. 34, no. 4, April 1999.

[2] C. T.-C. Nguyen, "Vibrating RF MEMS for next generation wireless applications," Proceedings, 2004 IEEE Custom Integrated Circuits Conf., Orlando, Florida, pp. 257-264, Oct. 36, 2004.

[3] F.D. Bannon, III, J.R. Clark, C.T.-C. Nguyen, "High-Q HF Microelectromechanical Filters", IEEE Journal of Solid-State Circuits, vol. 35, no. 4, April 2000.

[4] K. Wang, A.-C. Wong, C.T.-C. Nguyen, "VHF Free-Free Beam High-Q Micromechanical Resonators", Journal of Micromechanical Systems, vol. 9, no. 3, September 2000.

[5] E. Quévy, B. Legrand, D. Collard, L. Buchaillot, "Ultimate Technology For Micromachining Of Nanometric Gap HF Micromechanical Resonators", MEMS '03, 157, 2003

[6] S. Pourkamali and F. Ayazi, "SOI-Based HF and VHF Single-Crystal Silicon Resonators with Sub-100 Nanometer Vertical Capacitive Gaps", Transducers '03, 837-840, 2003

[7] J. Wang, Z. Ren, and C. T.-C. Nguyen, "Self-aligned 1.14$\mathrm{GHz}$ vibrating radial-mode disk resonators", Transducers'03, pp. 947-950, 2003.

[8] Y. Xie, S.-S. Li, Y.-W. Lin, Z. Ren, and C. T.-C. Nguyen, "UHF micromechanical extensional wine-glass mode ring resonators", IEDM '03, pp. 39.2.1 - 39.2.4, 2003.

[9] V. Kaajakari, et al., "Square-Extensional Mode SingleCrystal Silicon Micromechanical Resonator for Low-PhaseNoise Oscillator Applications", Electron Device Letters Vol. 25, Issue 4, pp. 173-175, April 2004.

[10] M. Puech, et al., "A Novel Plasma Release Process and a Super High Aspect Ratio using ICP Etching for MEMS", SEMICON, Japan, Dec. 2003. 